\title{
Mental health first aid for eating disorders: pilot evaluation of a training program for the public
}

\author{
Laura M Hart ${ }^{1 *}$, Anthony F Jorm ${ }^{1}$ and Susan J Paxton ${ }^{2}$
}

\begin{abstract}
Background: Eating disorders cause significant burden that may be reduced by early and appropriate help-seeking. However, despite the availability of effective treatments, very few individuals with eating disorders seek treatment. Training in mental health first aid is known to be effective in increasing mental health literacy and supportive behaviours, in the social networks of individuals with mental health problems. Increases in these domains are thought to improve the likelihood that effective help is sought. However, the efficacy of mental health first aid for eating disorders has not been evaluated. The aim of this research was to examine whether specific training in mental health first aid for eating disorders was effective in changing knowledge, attitudes and behaviours towards people with eating disorders.
\end{abstract}

Methods: A repeated measures, uncontrolled trial was conducted to establish proof of concept and provide guidance on the future design of a randomised controlled trial. Self-report questionnaires, administered at baseline, post-training and 6-month follow-up, assessed the effectiveness of the 4-hour, single session, mental health first aid training.

Results: 73 participants completed the training and all questionnaires. The training intervention was associated with statistically significant increases in problem recognition and knowledge of appropriate mental health first aid strategies, which were maintained at 6-month follow-up. Sustained significant changes in attitudes and behaviours were less clear. 20 participants reported providing assistance to someone with a suspected eating disorder, seven of whom sought professional help as a result of the first aid interaction. Results provided no evidence of a negative impact on participants or the individuals they provided assistance to.

Conclusions: This research provides preliminary evidence for the use of training in mental health first aid as a suitable intervention for increasing community knowledge of and support for people with eating disorders to seek appropriate help.

Trial registration: Australian New Zealand Clinical Trials Registry ACTRN12611001181998

\section{Background}

Effective, evidence-based treatments are available for eating disorders. Current treatments for bulimia, binge eating disorder and their sub-threshold counterparts are associated with good long-term outcomes, as follow-up studies show a majority return to health and functioning [1-3]. While further research and development is needed for the treatment of anorexia [4-6], many individuals achieve lasting recovery, and improvements in social

\footnotetext{
* Correspondence: Ihart@unimelb.edu.au

${ }^{1}$ Melbourne School of Population Health, University of Melbourne, Parkville VIC Australia

Full list of author information is available at the end of the article
}

functioning and quality of life are possible with current interventions, even where recovery is not attained $[7,8]$.

Despite the benefits of available treatments, only a minority of community members who experience an eating disorder seek appropriate care. It is estimated that less than one quarter of individuals with an eating disorder seek specific, evidence-based treatment [9]. Receiving treatment for weight-loss or another mental health problem, such as depression or anxiety, is much more common than receiving appropriate formal care for an eating pathology [10-13]. Those with eating disorders are also more likely to engage help-seeking from informal sources, such as their social network, or to use selfhelp strategies, such as increasing intake of vitamins and

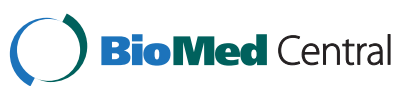


minerals or searching for information on the internet, than they are to obtain formal treatment [12,14-16]. While there are self-help strategies known to be useful in reducing some eating disorder symptoms, these are rarely utilised $[9,17]$.

Given that disordered eating and exercising cause significant personal, social and economic cost, effective treatment interventions that reduce symptoms and their associated burden are imperative for individuals with eating disorders [18-20]. There is, therefore, an immediate and widespread need for interventions that decrease barriers and increase incentives for seeking appropriate care $[13,21]$. If the significant burden imposed by eating disorders is to be decreased, research focused on the development, implementation and evaluation of effective programs for increasing help-seeking, is desperately needed.

Mental health literacy has been defined as knowledge and beliefs about mental illness that aid their recognition, management or prevention [22]. Interventions that aim to improve mental health literacy in the social network of individuals with eating disorders provide a promising avenue for increased help-seeking, because of the important role family and friends can play in recognising an eating disorder, reducing stigmatising attitudes, overcoming illness related barriers and facilitating engagement with treatment [21,23,24]. The social network of individuals with eating disorders is known to greatly influence the decision to seek treatment [21] and provide support and motivation for recovery [25,26]. Increasing the capacity of the social network is therefore likely to be a more effective strategy than increasing the knowledge of individuals with eating disorders alone.

One promising community-based intervention designed to increase mental health literacy is mental health first aid training. Mental health first aid is defined as the help provided to a person developing a mental health problem or experiencing a mental health crisis. The first aid is given until appropriate professional treatment is received, or the crisis resolves [27]. Mental health first aid techniques are taught in a 12-hour training program offered by Mental Health First Aid International (MHFA). MHFA was started in 2001 in response to Australian surveys revealing that the public lacked skills in responding to mental health problems [22,28,29]. Like the successful D.R.A.B.C action plan for emergency medical first aid, the MHFA training program utilises an action plan and provides information to the public about symptoms of various mental illnesses, their current effective treatments and how to assist individuals to manage symptoms and seek appropriate help (see Figure 1). MHFA has recently updated all of its training content to reflect the best practice consensus-based strategies developed over a series of Delphi studies [30-37]. MHFA courses are available in fifteen separate countries, including throughtout the United States, Canada, the United Kingdom, Europe and parts of Asia [38]. MHFA training courses have been well evaluated and found to be associated with changes in knowledge, attitude and behaviours [29,39-41]. Although a Delphi study has been completed to establish what the best practice strategies are for providing mental health first aid to someone with an eating disorder [42], prior to this research these recommendations had not yet been translated into a training intervention and their potential impact had not been evaluated.

The aim of the current study was to examine whether mental health first aid training for eating disorders was effective in changing knowledge, attitudes and behaviours towards people with eating disorders. It was expected that the single session training intervention would be associated with an increase in participant mental health literacy, a decrease in participants' stigmatising attitudes towards people with eating disorders, an increase in participants' provision of supportive first aid behaviours towards those with eating disorders, and the promotion of help-seeking among those who were recipients of first aid.

\section{Methods}

\section{Participants}

A desired sample size of $n=84$ was calculated based on a power analysis which assumed that, given no correlation between baseline and post-training scores, a sample of 64 participants would give $80 \%$ power to detect a medium effect size $(d=0.5)$ from baseline to posttraining with alpha $=0.05$ (Sample Power 2.0). This was increased to $n=84$ to allow for $30 \%$ drop-out $(n=20)$ between baseline and follow-up.

Participants were recruited from the residential halls and colleges affiliated with The University of Melbourne; a large metropolitan campus with a diverse student population [43]. All undergraduate students residing on campus were eligible to participate. These young adults were chosen for convenience sampling because they represent a group at very high risk of developing an eating disorder $[44,45]$, and a group who, given the nature of their residential environment, is likely to require skills in providing mental health first aid [46,47]. Welfare staff from campus residences were also included in the sample, as they were able to provide support to students who received the training, and were likely to be in contact with any individuals receiving treatment for an eating disorder.

Recruitment advertisements were posted as flyers on noticeboards around residences, presented orally at dinner meetings, or written in weekly news emails. The 


\section{Mental Health First Aid ACTION PLAN}

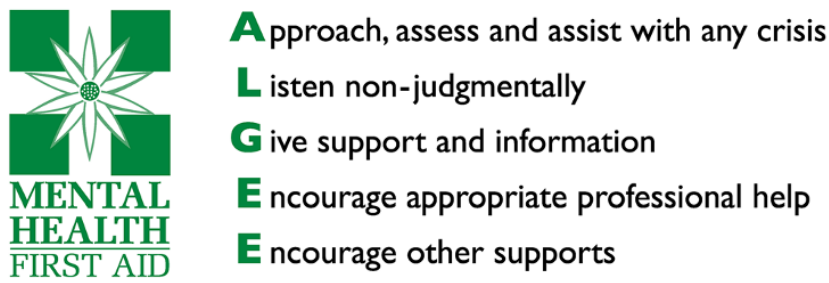

Figure 1 ALGEE action plan for providing mental health first aid. Mental health first aid techniques are taught in a 12-hour training program offered by the MHFA Training and Research Program. Like the successful D.R.A.B.C action plan for emergency medical first aid, the MHFA Training and Research program uses an action plan, ALGEE, to teach members of the public how to assist individuals with mental illness to manage symptoms and seek appropriate help.

advertisements included information about eating disorders and MHFA training. Student and staff training sessions were run separately. Approval for this research was granted by the University of Melbourne Human Research Ethics Committee.

\section{Intervention}

The training intervention was a 4-hour single-session, classroom-style, education program designed to be presented to groups of between 5 and 15 people. It included didactic teaching using a Powerpoint presentation, small-group learning activities (in pairs or threes) and whole-group discussion components. A teaching manual was developed to guide facilitation and ensure fidelity. Training was delivered by one primary instructor with a second facilitator assisting with group activities and participant questions. Both were trained and accredited MHFA Instructors [38].

The program content, presented across four consecutive units, is outlined in Table 1 . The structure and content were developed based on the successful model devised by the MHFA program [29,39]. The information presented on symptoms, possible causes, effective evidence-based treatments and early intervention was gleaned from reviews of current scientific literature. The information on warning signs and first aid strategies was based on the previously developed guidelines document Eating Disorders: First aid guidelines [42,48]. The training protocol and materials were assessed by a working group of experts in eating disorders or MHFA training, and a pilot session was conducted, prior to commencement of the research.

\section{Measures}

An assessment battery, including a range of self-report questionnaires, was designed to measure change in knowledge, attitudes and behaviours about eating disorders, as well as gather information about the demographic characteristics of participants and their mental health status.

Knowledge of eating disorder symptoms was assessed with a single item that asked participants to give a brief description of what you think the main signs or symptoms of an eating disorder might be. The open-ended responses were scored against the 25 'warning signs of a developing disorder' outlined in Eating Disorders: First

Table 1 Structure and content of the ‘Mental Health First Aid Training Course for Eating Disorders' intervention

\begin{tabular}{|c|c|c|c|}
\hline Unit 1: & Unit 2: & Unit 3: & Unit 4: \\
\hline Introduction & Eating Disorders & MHFA for eating disorders & Evaluation activity and conclusion \\
\hline Introductory activities & What are eating disorders? & First aid for crisis situations: & Post-training questionnaire \\
\hline $\begin{array}{l}\text { Common mental illnesses } \\
\text { occurring in youth }\end{array}$ & Signs of a developing disorder & i. Medical emergencies & Question and answer time \\
\hline Impact of mental illness & Importance of early intervention & ii. Suicidal thoughts and behaviours & $\begin{array}{l}\text { Handing out of certificates } \\
\text { and end matter }\end{array}$ \\
\hline Youth mental health first aid & Risk factors for eating disorders & iii. Non-suicidal self-injury & \\
\hline The MHFA action plan & $\begin{array}{l}\text { MHFA for eating disorders - } \\
\text { Action } 1\end{array}$ & MHFA for eating disorders - Actions 2-5 & \\
\hline 1 hour & 1 hour & 1.5 hours & 0.5 hours \\
\hline
\end{tabular}


aid guidelines [48]; one point was awarded for each warning sign mentioned. The inter-rater reliability for scoring items was $r=0.94$. This research was the first implementation of this measure.

Accurate problem recognition, knowledge of effective treatments and interventions, and attitudes towards bulimia, were assessed using the Mental Health Literacy Questionnaire for Bulimic Type Eating Disorders (MHLQ-B). The MHLQ-B was developed for the Health and Well-Being study by Mond and colleagues [49] and has been widely used in the study of eating disorder mental health literacy. The questionnaire begins with a vignette describing a fictional young adult woman 'Kelly' whose symptoms meet DSM-IV-TR diagnostic criteria for bulimia purging subtype.

A knowledge of effective treatments and professionals scale was constructed from the three questions on the MHLQ-B assessing knowledge of individuals who might be helpful (15 items), knowledge of treatments or activities (16 items) and knowledge of medications (eight items). Seven items were selected to construct the scale, based on the evidence in the current treatment literature, and the recommendations in the Eating Disorders: First aid guidelines [48], which suggest that psychologists, psychiatrists, dietitians/nutritionists, GPs, CBT, getting advice about diet and nutrition, and antidepressants, are all effective for eating disorders, and can therefore be considered 'helpful' for bulimia. Hence, participant responses were scored from zero (none of these items rated as 'helpful') to seven (all items rated as 'helpful'). Although this approach has been used to assess knowledge of treatments for depression in previous evaluations of MHFA training [50], this research was the first time this measure had been used to assess knowledge of effective treatments and professionals for eating disorders.

A novel addition to the analyses of the MHLQ-B was the inclusion of the knowledge of informal help-seeking scale. Because there are informal activities known to facilitate formal treatment seeking or the management of disordered eating symptoms, the current research also sought to quantify how knowledge about broader helpseeking activities changes in response to the training program. From the 40 -item list of individuals, treatments or activities, and medications, provided in the MHLQ-B, those that were recommended in the Eating Disorders: First aid guidelines [48], as appropriate and helpful, were used to construct the scale: friends, family members, using a self-help treatment manual and getting information about problem eating and available services. Hence, participant responses were scored from zero (none of these items rated as 'helpful') to four (all items rated as 'helpful').

The First Aid Knowledge Test (FAKT) was developed for use in the current research to test participant knowledge of best practice first aid strategies, as outlined in Eating Disorders: First aid guidelines [48]. It contains 26 true/false statements regarding knowledge and behaviours required for providing optimal mental health first aid. Responses are via a single forced-choice selection from the options: 'Agree', 'Disagree' or 'Not sure'. One point is given for each answer that concurs with the information in the guidelines (i.e. an 'agree' response in relation to a true statement), resulting in a possible total score range of $0-26$. The measure was validated with pilot testing.

The Social Distance Scale assesses levels of social rejection that members of the community are likely to impose on individuals with mental illness [51]. It comprises seven questions that ask how likely a participant is to react to a person with mental illness, as described by an accompanying vignette. Each question is rated on a 4point Likert scale ( 1 = 'definitely willing' to 4 = 'definitely unwilling') [52]. A composite measure of social distance is calculated by adding across all items, with higher scores indicating a greater degree of desired social distance and more negative attitudes towards people with mental illness. In the current research possible total scores ranged from 0-35.

The Level of Contact Report [53] measures how familiar members of the public are (what level of contact they have) with individuals with mental illness. It was developed to examine whether level of familiarity had any effect on stigmatising attitudes, such as perceiving a person with schizophrenia as dangerous or unpredictable. The instrument lists 12 situations involving contact with an individual with mental illness. The highest score reported by a participant is taken as the total score. In the current research all items were modified to be specific to eating disorders, such that all references to 'mental illness' were replaced with 'eating disorder'.

Throughout the questionnaire battery, six items were included to assess participants' provision of mental health first aid to individuals with eating disorders, knowledge of the MHFA action plan and confidence in providing assistance. They were: (1) In the last 6 months have you had contact with anyone who you think might have an eating disorder? (2) If 'yes', how many? (3) If you have had contact with someone who has an eating disorder, in the last 6 months, have you offered them any help? (4) If you offered help, what type of help was it? (5) If Kelly was someone you knew and cared about, how would you help her? (6) If you had contact with someone who had a problem like Kelly's, how confident would you feel in helping them? The items were based on those used in previous MHFA training evaluations [50,54-56]. Items 1,3 and 6 required forced-choice responses, while items 2, 4 and 5 were open-ended. Responses to item 4 were coded into one of nine categories according to 
recurring themes. Category frequencies were then assessed across time points. Responses to item 5 were scored against the six components within the MHFA action plan (see Figure 1). Because the first action $A-$ approach the person, assess and assist with any crisis contained many concepts, this was split into two categories (approach and assess/assist). The remaining four actions comprised one category each. For each of the six categories, responses were scored out of two points: a score of two was given if participants correctly described an action and provided specific detail about how they would undertake that action; a score of one was given if they mentioned the action but did not provide detail on how it may occur; and a score of zero was given if the action was not mentioned. A total score was calculated by adding together the scores for each of the categories, with a possible total score falling between $0-12$. The inter-rater reliability on these items was $r=0.91$. This scoring system has been used in previous research investigating MHFA action plan knowledge [40,57].

The First Aid Experiences Questionnaire was developed by Jorm, Kitchener and Mugford [56] for a follow-up study of participants who had attended MHFA training. It is designed to elicit open-ended information about helping behaviours towards individuals with mental health problems and about what the perceived effect of those behaviours was. The questionnaire has also been used in research investigating the utility and impact of accessing MHFA guidelines on the internet [58]. To assess whether the information provided in the training program was generalised to illnesses other than eating disorders, the questionnaire also asked whether participants had provided first aid to individuals who were experiencing mental health problems other than an eating disorder.

Given that some previous research has found that providing preventive interventions, which describe eating disorder symptoms, can lead to increases in eating pathology [59,60] The Eating Disorders Examination Questionnaire (EDE-Q) [61] was used in the current research to assess for any negative impact on participants' eating pathology. The EDE-Q is currently considered the gold-standard for eating disorder research [62-66]. Australian research suggests that a global score of 2.8 reliably predicts clinical eating disorder status in females [65], however, a reliable cut-off has not yet been established for males.

The K10, a general measure of non-specific psychological distress, was also used to assess for any negative impact on participant psychopathology. Total scores range from 10-50, with higher scores indicating a higher level of distress [67].

\section{Design and analyses}

The effectiveness of the training program was evaluated using an uncontrolled, repeated measures design. The assessment battery was administered at three time points: before the training course commenced (baseline), immediately after training concluded (post-training) and 6 months after the training program was completed (follow-up). Table 2 shows which measures were employed across each assessment time point. Because the measures of behaviour and mental health measured a time frame greater than one week, these were administered at baseline and follow-up only. The primary outcomes of interest were the problem recognition item within the MHLQ-B and the FAKT.

Repeated measures ANOVAs were used for continuous measures completed at all three time points. Where assumptions of sphericity where violated, the HunyhFeldt method for adjusting degrees of freedom was used [68]. Where the omnibus test was significant, planned contrasts were conducted to assess whether there was a significant change from baseline to post-training and baseline to follow-up. Dependent (paired) samples twotailed $t$-tests were used for continuous measures completed at baseline and follow-up only. For ordinal data, Friedman's ANOVA was used and Wilcoxon signed-rank tests were then conducted where the omnibus test was significant $[68,69]$. For dichotomous data, a Cochran's Q test was used for $k$ samples and the McNemar test for paired comparisons $[68,69]$. A Pearson's chi-square analysis was conducted in the assessment of whether there were differences in first aid experiences between staff and students in the sample, because these groups were independent. Unless corrections for inflated error rate were required, all tests were conducted using $\alpha<.05$. For open-ended responses, thematic analysis was used to section data into commonly occurring categories, which could then be assessed for frequency.

\section{Procedures}

Prior to attending the training program, participants were sent an electronic link to the baseline questionnaire, hosted by an online survey software system (surveymonkey.com). Immediately after the training, participants completed the post-training questionnaire and an electronic link to the follow-up questionnaire was sent to each participant's email address 182 days (6 months) after the date of attendance at the training program. Personalised email and SMS text prompts were sent at one week intervals, for a maximum of three weeks, to remind participants to complete the questionnaire.

\section{Results}

\section{Participants}

\section{Characteristics at baseline}

Ninety participants completed the baseline questionnaire. Participant characteristics are shown in Table 3. Participants ranged in age from 17 to 62 years 
Table 2 Instruments administered to measure knowledge, attitudes behaviour and mental health status of participants, across time points

\begin{tabular}{|c|c|c|c|c|}
\hline Variable measured & Instrument & Baseline & Post-training & Follow-up \\
\hline \multirow[t]{8}{*}{ Knowledge } & Knowledge of Eating Disorder Symptoms & $\checkmark$ & $\checkmark$ & $\checkmark$ \\
\hline & MHLQ-B & & & \\
\hline & problem recognition & $\checkmark$ & $\checkmark$ & $\checkmark$ \\
\hline & knowledge of effective treatments scale & $\checkmark$ & $\checkmark$ & $\checkmark$ \\
\hline & knowledge of informal help-seeking scale & $\checkmark$ & $\checkmark$ & $\checkmark$ \\
\hline & First Aid Knowledge Test & $\checkmark$ & $\checkmark$ & $\checkmark$ \\
\hline & Mental Health First Aid Questions & & & \\
\hline & item 5 - ALGEE & $\checkmark$ & $\checkmark$ & $\checkmark$ \\
\hline \multirow[t]{3}{*}{ Attitudes } & Social Distance Scale & $\checkmark$ & $\checkmark$ & $\checkmark$ \\
\hline & MHLQ-B & & & \\
\hline & Beliefs about bulimia (3 items) & $\checkmark$ & $\checkmark$ & $\checkmark$ \\
\hline \multirow[t]{8}{*}{ Behaviour } & Level of Contact Report & $\checkmark$ & & $\checkmark$ \\
\hline & Mental Health First Aid Questions & & & \\
\hline & item 1 - Any contact & $\checkmark$ & & $\checkmark$ \\
\hline & item 2 - Number of contacts & $\checkmark$ & & $\checkmark$ \\
\hline & item 3 - Amount of help & $\checkmark$ & & $\checkmark$ \\
\hline & item 4 - Type of help & $\checkmark$ & & $\checkmark$ \\
\hline & item 6 - Confidence & $\checkmark$ & $\checkmark$ & $\checkmark$ \\
\hline & First Aid Experiences Questionnaire & & & $\checkmark$ \\
\hline \multirow[t]{2}{*}{ Mental Health Status } & EDE-Q & $\checkmark$ & & $\checkmark$ \\
\hline & K10 & $\checkmark$ & & $\checkmark$ \\
\hline
\end{tabular}

$(M=23.84, S D=10.43)$. Participants had studied at the tertiary level, on average, for 2.68 years $(S D=3.16)$. A very small number indicated they had received prior training in eating disorders or mental health, the majority of whom were staff acting in a welfare capacity at their college. Similarly, very few participants indicated that they had read the previously developed guidelines prior to attending the training.

The mean EDE-Q Global score for females in the sample was $1.52(S D=1.12)$ indicating normative

Table 3 Characteristics of participants completing baseline and follow-up questionnaires

\begin{tabular}{|c|c|c|c|c|c|c|}
\hline & \multirow{2}{*}{\multicolumn{2}{|c|}{$\begin{array}{c}\text { Baseline } \\
(n=90)\end{array}$}} & \multirow{2}{*}{\multicolumn{2}{|c|}{$\begin{array}{c}\text { Post-training } \\
(n=82)\end{array}$}} & \multirow{2}{*}{\multicolumn{2}{|c|}{$\begin{array}{c}\text { Follow-up } \\
(n=73)\end{array}$}} \\
\hline & & & & & & \\
\hline & $\mathrm{n}$ & $\%$ & $\mathbf{n}$ & $\%$ & $\mathrm{n}$ & $\%$ \\
\hline Female & 51 & 56.7 & 45 & 54.9 & 43 & 58.9 \\
\hline Staff & 21 & 23.3 & 20 & 24.4 & 20 & 27.4 \\
\hline Student & 69 & 76.7 & 62 & 75.6 & 53 & 72.6 \\
\hline Born in Australia & 67 & 74.4 & 60 & 73.2 & 53 & 72.6 \\
\hline English second language & 7 & 7.8 & 7 & 8.5 & 7 & 9.6 \\
\hline Attended MHFA course & 5 & 5.6 & 5 & 6.1 & 5 & 6.9 \\
\hline Read ED guidelines & 4 & 4.4 & 3 & 3.7 & 3 & 4.1 \\
\hline Attended ED course & 5 & 5.6 & 5 & 6.1 & 5 & 6.9 \\
\hline
\end{tabular}

eating pathology (e.g. $M=1.52, S D=1.25$ ) [70]. The score for males was $0.83(S D=0.70)$, indicating the sample scored slightly lower (less pathological) than normative (e.g. $M=1.09, S D=1.00$ ) [71]. This finding may be due to the inclusion of staff in the current sample, who were older than the sample used to establish norms, and the trend for EDE-Q scores to decrease with age [70]. Seven female participants scored above 2.80 , suggesting they were likely to be experiencing a clinically significant eating disorder [63]. Cut-off scores for establishing probable diagnoses in community samples of males have not yet been reported. However, they are likely to be lower than that for females. No males scored above 2.8, although, two scored above 2.50 .

The mean total K10 score was $18.1(S D=4.78)$, indicating scores were higher than normative (e.g. $M=14.20$ ) [67]. Nine participants scored above 25; according to Australian national survey data, 38\% of individuals who score in this range will experience a clinically significant affective disorder [67].

\section{Participant flow}

Flow of participants through the research stages is shown in Figure 2. Ninety-one percent of the 90 
participants who completed the baseline questionnaire went on to complete the training and the post-training questionnaire. No statistically significant differences were found at baseline between those participants who completed the training and the post-training questionnaire and those who did not. Eighty-one percent of baseline participants went on to complete all three questionnaires. There were also no statistically significant differences found at baseline between those participants who completed the follow-up questionnaire and those who did not. Because of the small number who failed to complete all three stages of the evaluation $(n=17)$, and the lack of any significant difference between completers and drop-outs, the participants who did not complete the post-training or follow-up questionnaires were excluded from further analyses.

\section{Knowledge}

Results for the instruments assessing participant knowledge are shown in Table 4. Mean scores on knowledge of eating disorder symptoms remained stable over time and no significant difference was found between scores at baseline, post-training and follow-up.

When asked what they thought was 'Kelly's main problem' the majority of participants recognised the symptoms in the vignette as relating to a general mental health problem such as 'low self-esteem or lack of confidence' or 'mental illness'. Although many correctly recognised Kelly's problem at baseline as 'bulimia nervosa', the proportion increased significantly from baseline to post-training. However, this dropped at follow-up and was no longer significantly different from baseline. To assess whether recognition of the problem as any eating disorder changed over time, the proportion of

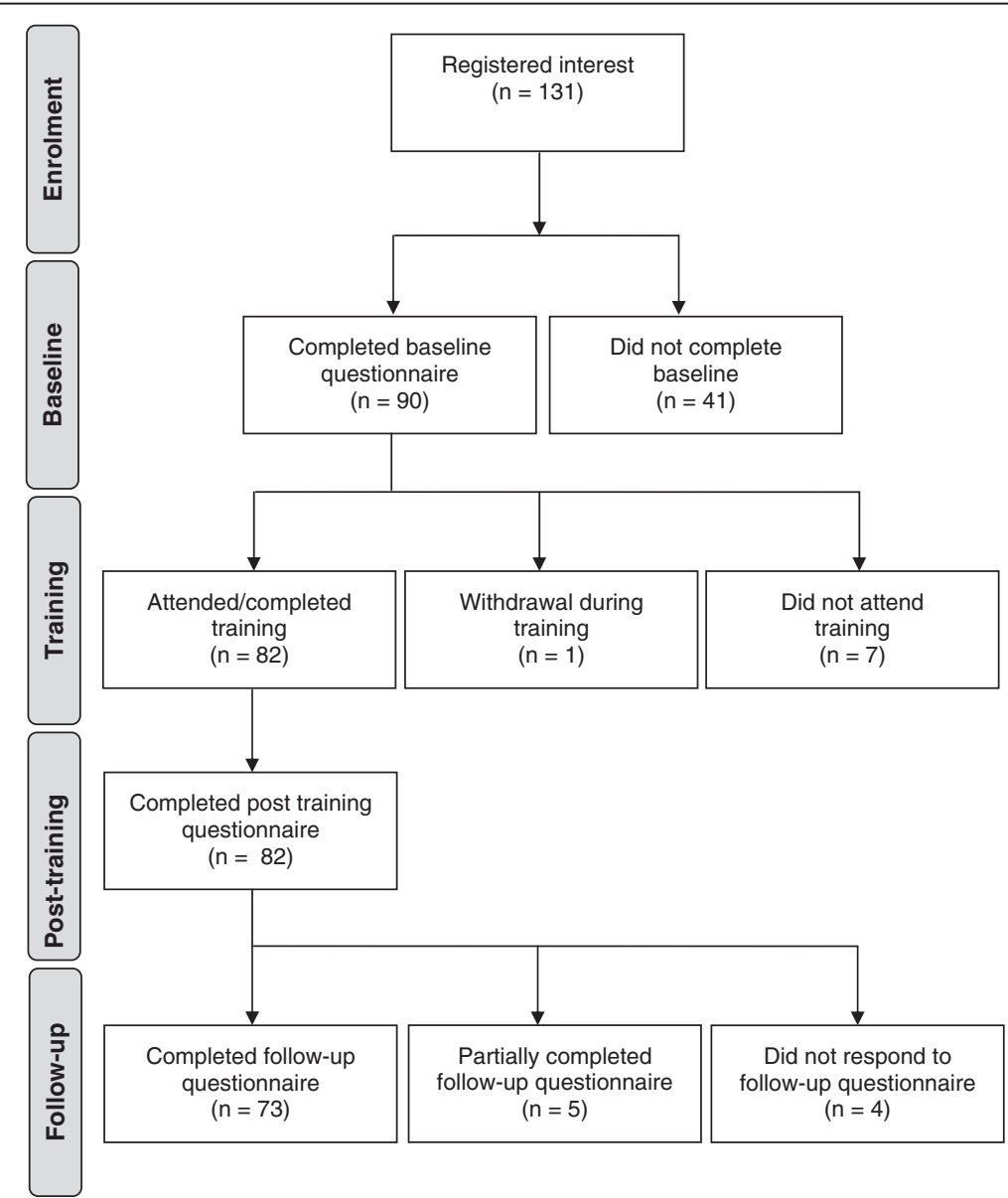

Figure 2 Participant flow through research stages. 90 participants completed the baseline questionnaire. 91\% of these participants went on to complete both the training and the post-training questionnaire. No statistically significant differences were found at baseline, between those participants who completed the training and the post-training questionnaire, and those who did not. 73 participants ( $81 \%$ of baseline) completed the follow-up questionnaire 6-months after training. Five participants began the follow-up questionnaire but completed less than 50\%. There were no participants who responded to more than $50 \%$ but less than $100 \%$ of the questionnaire. No statistically significant differences were found at baseline between those participants who completed the follow-up questionnaire and those who did not. Participants who did not complete the post-training or follow-up questionnaires were excluded from further analyses. 
Table 4 Results for instruments assessing changes in knowledge and attitudes

\begin{tabular}{|c|c|c|c|c|c|c|}
\hline Instrument & Baseline & Post-training & Follow-up & Sig Test & $\begin{array}{l}\text { Change Baseline } \\
\text { to Post-training }\end{array}$ & $\begin{array}{c}\text { Change Baseline } \\
\text { to Follow-up }\end{array}$ \\
\hline Knowledge of Eating Disorder Symptoms (mean total score) & 3.4 & 3.4 & 3.1 & $p=.4$ & & \\
\hline \multicolumn{7}{|l|}{ MHLQ-B } \\
\hline Problem recognised as BN (\%) & 17.8 & 42.5 & 28.8 & $p=.001$ & $p<.001$ & $p=.115$ \\
\hline Problem recognised as any $E D^{A}(\%)$ & 45.2 & 78.1 & 64.4 & $p<.001$ & $p<.001$ & $p=.007$ \\
\hline Problem recognised as general mental health problem ${ }^{\mathrm{B}}(\%)$ & 49.3 & 21.9 & 27.4 & $p<.001$ & $p<.001$ & $p=.002$ \\
\hline knowledge of effective treatments scale ${ }^{C}$ (mean total score) & 4.7 & 6.4 & 5.4 & $p<.001$ & $p<.001$ & $p<.001$ \\
\hline knowledge of informal help-seeking scale (mean total score) & 2.8 & 3.2 & 3.0 & $p=.007$ & $p=.004$ & $p=.054$ \\
\hline First Aid Knowledge Test (mean total score) & 16.1 & 23.2 & 20.4 & $p<.001$ & $p<.001$ & $p<.001$ \\
\hline \multicolumn{7}{|l|}{ Mental Health First Aid Questions } \\
\hline item 5 - ALGEE (mean total score) & 2.0 & 4.0 & 3.0 & $p<.001$ & $p<.001$ & $p=.089$ \\
\hline Social Distance Scale (mean total score) & 16.0 & 16.2 & 15.6 & & & \\
\hline \multicolumn{7}{|l|}{ MHLQ-B } \\
\hline $\begin{array}{l}\text { How distressing do you think it would be to have } \\
\text { Kelly's problem? }\end{array}$ & $p=.51$ & & & & & \\
\hline Extremely (\%) & 38.4 & 39.7 & 43.8 & & & \\
\hline Very (\%) & 53.4 & 56.2 & 49.3 & & & \\
\hline Moderately (\%) & 8.2 & 4.1 & 6.8 & & & \\
\hline A little (\%) & 0.0 & 0.0 & 0.0 & & & \\
\hline Not at all (\%) & 0.0 & 0.0 & 0.0 & & & \\
\hline $\begin{array}{l}\text { How sympathetic would you be towards someone with } \\
\text { Kelly's problem? }\end{array}$ & $p=.002$ & $p=.001$ & $p=.17$ & & & \\
\hline Extremely (\%) & 24.7 & 39.7 & 30.1 & & & \\
\hline Very (\%) & 56.2 & 50.7 & 53.4 & & & \\
\hline Moderately (\%) & 16.4 & 9.6 & 16.4 & & & \\
\hline A little (\%) & 2.7 & 0.0 & 0.0 & & & \\
\hline Not at all (\%) & 0.0 & 0.0 & 0.0 & & & \\
\hline $\begin{array}{l}\text { Have you ever thought it might not be too bad } \\
\text { to be like Kelly? }\end{array}$ & $p=.07$ & & & & & \\
\hline Always (\%) & 1.4 & 0.0 & 1.4 & & & \\
\hline Often (\%) & 6.8 & 5.5 & 6.8 & & & \\
\hline Occasionally (\%) & 19.2 & 16.4 & 19.2 & & & \\
\hline Rarely (\%) & 30.1 & 30.1 & 31.5 & & & \\
\hline Never (\%) & 42.5 & 47.9 & 41.1 & & & \\
\hline
\end{tabular}

A Any ED included use of the labels 'bulimia nervosa', 'anorexia nervosa' or 'a binge eating disorder or problem'.

${ }^{B}$ Any mental health problem included use of the labels 'an anxiety disorder or problem', 'mental illness', 'depression' or 'low self-esteem or lack of self-worth'.

C This included items that were considered to have evidence for efficacy or recommended in treatment guidelines for BN: antidepressants, cognitive behavioural therapy, getting advice about diet or nutrition, GP, psychiatrist, psychologist.

participants responding 'bulimia nervosa, 'a binge eating disorder or problem' or 'anorexia nervosa', were assessed together. The proportion recognising the problem as any eating disorder increased significantly from baseline to post-training, and despite a fall at follow-up, was still significantly different to baseline levels. To assess whether recognition of the problem in the vignette, as a general mental health problem, changed over time, the frequency of all other responses representing a mental health related condition were assessed together ('an anxiety disorder or problem, 'mental illness', 'depression', 'low self-esteem or lack of self-confidence'). There was a significant decrease in frequency from baseline to posttraining and this was maintained at follow-up.

At baseline, participants scored an average of 4.7 points out of 7 on the Knowledge of effective treatments and professionals scale. Scores were significantly different across time points, with both post-training and follow-up scores being significantly higher than baseline. On the Knowledge of informal help-seeking scale participants scored an 
average of 2.8 out of 4 . Again, scores were significantly different across time points, with post-training scores being significantly higher than baseline, however, after a decline in scores at follow-up these were no longer significantly different from baseline.

At baseline participants scored an average of 16.1 of a possible 26 on the FAKT. Scores were significantly different across time points, with both post-training and follow-up scores a significant improvement on baseline.

The fifth Mental Health First Aid item asked participants how they would help someone like Kelly. Average ALGEE action plan scores were significantly different across time points, however, while post-training scores were a significant improvement on baseline, this was not maintained at follow-up and scores were no longer significantly different from baseline.

\section{Attitudes}

Results for the instruments assessing participant attitudes are also shown in Table 4. Scores on the Social Distance Scale remained stable and were not significantly different across time points. Participant attitudes towards bulimia were assessed via three items on the MHLQ-B. Responses to the first item How distressing do you think it would be to have Kelly's problem? showed that a large majority of participants (>90\%), across all three time points, believed it would be either 'very' or 'extremely' distressing to have Kelly's problem. Although the percentage of participants who believed it would be extremely distressing, increased from $38 \%$ at baseline to $40 \%$ at post-training, then to $44 \%$ at follow-up, the ombnibus significance test found no significant differences in scores over time.

Responses to the item How sympathetic would you be towards someone with Kelly's problem? revealed that the majority of participants, across all three time points, believed they would be 'very' or 'extremely' sympathetic towards someone with Kelly's problem. Significant differences were found in responses over time. However, while there was a significant change in ratings from baseline to post-training, a comparison of baseline and follow up revealed no significant change. That the ratings of 'extremely' increased and ratings of 'moderately' decreased from baseline to post-training, though returned to baseline levels at follow-up, may have largely accounted for this finding.

Responses to the item Have you ever thought it might not be too bad to be like Kelly, given that she has been able to lose a lot of weight? showed that majority of participants reported that they had 'never' or 'rarely' thought it desirable to be like Kelly. These responses appeared stable over time and an omnibus test revealed no significant differences in ratings across the time points.

\section{Behaviours}

Results for the instruments assessing participant behaviors are shown in Table 5. At baseline, the mean Level of Contact Report score was 7.49 of a possible 12, indicating that participants had experienced a medium level of contact with individuals with eating disorders. Significance testing revealed that there were no significant changes in scores over time.

In response to the question In the last 6 months have you had contact with anyone who you think might have an eating disorder? 60\% said 'yes' at baseline. The modal number of contacts was 1 person $(n=19)$, and the total number of contacts reported by participants was 78 . At follow-up, despite a small drop in the frequency of participants reporting that they had contact with someone with an eating disorder (56\%), the modal number was 2 people $(n=16)$, and the total number of contacts was 97 . Twenty-two participants reported an increase in the amount of contact across time. These changes, however, were not statistically significant. In addition, no statistically significant changes were found between baseline and follow-up for the items assessing the amount of assistance given and the type of assistance given.

Results for the final Mental Health First Aid question regarding participant confidence revealed that confidence ratings were significantly different across time points, with both post-training, and follow-up ratings being significantly higher than baseline.

To assess the qualitative nature of first aid interactions participants had with individuals with eating disorders, the First Aid Experiences Questionnaire asked a number of open-ended questions about their intervention. Of the 73 participants in the total sample, $41 \%(n=30)$ of participants provided feedback on their first aid experiences. Those who did not report on a first aid experience $(n=43,59 \%)$ were asked a series of open-ended questions about what they would do in the future if a situation arose. Responses to these are shown in Table 6. For those who did experience a first aid situation a different series of questions, about whether the participant had been able to assist the person and how they felt the intervention had gone, were presented. Responses to these questions are shown in Table 7. A full description of the qualitative data, including descriptions of first aid provided to individuals experiencing a mental health problem other than an eating disorder, is given in Additional file 1: Document 1.

\section{Mental health status}

A statistically significant reduction in the mean EDE-Q global score was found between baseline $(M=1.2)$ and follow-up $(M=1.1)$, indicating a reduction in eating disorder psychopathology $t(72)=2.27, p=.026$. 
Table 5 Results for instruments assessing changes in behaviour

\begin{tabular}{|c|c|c|c|}
\hline Instrument & Baseline & Follow-up & Sig Test \\
\hline Level of Contact Report (mean highest score) & 7.49 & 7.57 & $p=.783$ \\
\hline \multicolumn{4}{|l|}{ Mental Health First Aid Questions } \\
\hline item 1 - Any contact & & & $p=.768$ \\
\hline Yes (\%) & 60 & 56 & \\
\hline No (\%) & 26 & 30 & \\
\hline Not sure (\%) & 14 & 14 & \\
\hline item 2 - Number of contacts ${ }^{A}$ & & & $p=.95$ \\
\hline Contact with 1 person $(n, \%)$ & $19,47.5$ & $13,31.7$ & \\
\hline Contact with 2 people $(n, \%)$ & $11,27.5$ & $16,39.0$ & \\
\hline Contact with 3 people $(n, \%)$ & $7,17.5$ & $10,24.4$ & \\
\hline Contact with 4 or more people $(n, \%)$ & $3,7.5$ & $2,4.9$ & \\
\hline item 3 - Amount of help ${ }^{A}$ & & & $p=.08$ \\
\hline No help provided $(n, \%)$ & $17,38.6$ & $11,26.8$ & \\
\hline A little $(n, \%)$ & $12,27.3$ & $15,36.6$ & \\
\hline Some $(n, \%)$ & $12,27.3$ & $12,29.3$ & \\
\hline A lot $(n, \%)$ & $3,6.8$ & $3,7.3$ & \\
\hline \multicolumn{4}{|l|}{ item 4 - Type of help ${ }^{B}$} \\
\hline Asked someone more appropriate than myself to help the person $(n, \%)$ & $3,10.7$ & $8,25.8$ & $p=.18$ \\
\hline Talked to the person directly $(n, \%)$ & 15,53 & $15,48.4$ & $p=1.0$ \\
\hline Offered general support $(n, \%)$ & $6,21.4$ & $3,9.7$ & $p=.45$ \\
\hline Offered information about illness/services $(n, \%)$ & $3,10.7$ & $5,16.1$ & $p=.72$ \\
\hline Encouraged/assisted with seeking prof help $(n, \%)$ & $4,14.3$ & $9,29.0$ & $p=.23$ \\
\hline Encouraged self help $(n, \%)$ & $1,3.6$ & $4,12.9$ & $p=.38$ \\
\hline Offered practical help $(n, \%)$ & $6,21.4$ & $2,6.5$ & $p=.29$ \\
\hline Offered emotional support $(n, \%)$ & $11,39.3$ & $8,25.8$ & $p=.61$ \\
\hline Risk assessment/monitoring ( $n, \%)$ & $1,3.6$ & $4,12.9$ & $p=.38$ \\
\hline item 6 - Confidence in helping Kelly (mean score) & 2.2 & 2.7 & $p<.001$ \\
\hline Not at all $(n, \%)$ & $16,21.9$ & $3,4.1$ & \\
\hline A little $(n, \%)$ & $34,46.6$ & 27,37 & \\
\hline Moderately $(n, \%)$ & $17,23.3$ & $34,46.6$ & \\
\hline Quite a bit $(n, \%)$ & $6,8.2$ & $9,12.3$ & \\
\hline Extremely $(n, \%)$ & $0,0.0$ & $0,0.0$ & \\
\hline
\end{tabular}

$\mathrm{A}_{\mathrm{B}}=$ Data is for 44 participants at baseline and 41 at follow-up (ie. Only those who reported having had contact with someone with an ED).

${ }^{\mathrm{B}}=$ Data is for 28 participants at baseline and 31 at follow-up (ie. Not all of those who reported contact also offered assistance. This data is only for those who offered assistance).

The mean total K10 score dropped slightly from baseline $(M=18.1)$ to follow-up $(M=17.2)$, though no statistically significant differences were found across the two time points $t(72)=1.53, p=.129$.

\section{Discussion}

The aim of the current study was to examine whether a training intervention on mental health first aid for eating disorders was effective in changing knowledge, attitudes and behaviours towards people with eating disorders.
Results suggest that the training intervention was associated with significant improvements in knowledge, which were maintained over time. There was no evidence to suggest the training program produced sustained changes in attitudes towards individuals with eating disorders, though these were relatively empathic at baseline. There was also little quantitative evidence to suggest the training program produced significant changes in behaviours towards individuals with eating disorders, however, qualitative responses in the small sample who did have contact with an individual with an 
Table 6 Responses to the First Aid Experiences Questionnaire for participants who did not report experiencing a first aid situation $(n=43)$

\begin{tabular}{|c|c|c|}
\hline & n & $\%$ \\
\hline \multicolumn{3}{|l|}{ Q1. Is this what you would have expected, or is it somewhat surprising not to have come across such a situation?* } \\
\hline Surprised & 17 & 39.5 \\
\hline Had expected to encounter someone with an eating disorder & 17 & 39.5 \\
\hline Had been in contact, but didn't provide first aid because we were not good enough friends & 8 & 18.6 \\
\hline Had been in contact with someone with an ED before the training and this continued after the training & 3 & 7.0 \\
\hline \multicolumn{3}{|c|}{$\begin{array}{l}\text { Q2. In the future, if you were to come across someone who you believed was experiencing an eating disorder, how well prepared would you feel to deal } \\
\text { with the situation?* }\end{array}$} \\
\hline Very well, or well prepared & 33 & 76.7 \\
\hline Prepared & 9 & 20.9 \\
\hline Prepared but uneasy & 5 & 11.6 \\
\hline Not at all prepared & 1 & 2.3 \\
\hline \multicolumn{3}{|c|}{$\begin{array}{l}\text { Q3. How has attending 'Mental Health First Aid Training Course for Eating Disorders' changed how you relate to or feel about people who experience } \\
\text { eating disorders?* }\end{array}$} \\
\hline Know more about EDs & 15 & 34.9 \\
\hline Know more/more confident about how to help & 14 & 32.6 \\
\hline More empathy for those with EDs & 14 & 32.6 \\
\hline No change because of prior expertise & 2 & 4.7 \\
\hline No change & 4 & 9.3 \\
\hline
\end{tabular}

* Responses were open-ended and therefore participants may have mentioned multiple ideas/categories.

eating disorder, suggested the training was associated with changes in first aid behaviours.

\section{Changes in knowledge}

There was no significant change in the knowledge of eating disorder symptoms across time. It is possible that this finding is the result of participants lodging less detailed or less specific answers across time, as the follow-up questionnaire was sent to the majority of participants between October and November; a busy exam period and the end of the academic year. It is also possible that the training failed to produce a significant increase in knowledge scores over time because there was not enough emphasis placed on eating disorder specific signs and symptoms throughout the curriculum. In fact, the training emphasises the importance of recognising the development of non-specific signs of distress, as this is the best opportunity to provide timely mental health first aid. As such, participants were taught to look for a change in "a person's thinking, emotional state and behaviour, which disrupts the ability to work or carry out other daily activities and engage in satisfying personal relationships" [27], which is how the MHFA program defines the onset of a mental health problem. Future evaluations may therefore benefit from an item designed to measure a change in knowledge regarding the most appropriate time to provide mental health first aid, rather than specific knowledge relating to the wide range of eating disorder signs and symptoms.
Unlike knowledge of signs and symptoms, accurate recognition of the problem in the MHLQ-B vignette, as 'bulimia nervosa', increased significantly immediately after the training. Furthermore, recognition of the problem as any eating disorder also increased, and this change was sustained over time. Importantly, this effect of increased recognition, was not generalised to any mental health problem; participants were not more likely to label the problem in the vignette with general terms relating to mental ill-health at follow-up, indicating that the improved recognition was specific to eating disorders, and in particular to bulimia. It is interesting that participants' increased recognition of the problem as any eating disorder was more robust than the specific recognition of the problem as bulimia. Given that the training encourages participants to look for changes in eating and exercise behaviours that are interfering with function, rather than encouraging participants to look for indicators of diagnostic categories, this result is perhaps more desirable than having a sustained increase in the specific recognition of the problem as bulimia.

The Knowledge of effective treatments and professionals scale in the MHLQ-B showed that participants' knowledge of effective treatments for eating disorders also significantly improved over time. Unfortunately this was not true for the Knowledge of informal help-seeking scale. While it was found that total scale scores significantly improved after the training, these improvements were not maintained at follow-up. This result, however, 
Table 7 Responses to the First Aid Experiences Questionnaire for participants who did report experiencing a first aid situation $(n=30)$

\begin{tabular}{lcc}
\hline & $\mathbf{n}$ & $\%$ \\
\hline Q1. In what capacity do you attend the college? & 22 & 73.3 \\
Student & 7 & 26.7 \\
Staff & 7
\end{tabular}

Q2. Could you tell us something about the situation(s) and the problem(s) you believed the person was experiencing?*

Change in eating habits (ate less/restricted diet) 15

Binge eating

50.0

Change in exercise patterns

Vomiting

Q3. Did you try to assist the person you thought might be developing or experiencing an eating disorder?

$$
\text { No }
$$

Q4. What was the reason(s) that you were not able to assist that person?* $(n=10)$

Not close enough to the person/others more appropriate to provide first aid

Person already adequate receiving support/care

Assistance refused

Q5. Can you give us an example of something you did to assist the person?* $(n=20)$

Approached the person, discussed my concerns, listened to them

Discussed my concerns with someone more appropriate to provide first aid

Offered information and resources about EDs

Encouraged the person to seek help

Q6. When assisting the person did you use the information provided in the 'Mental Health First Aid Training Course for Eating Disorders'? ( $n=20$ )

Yes

No

Not sure

Q7. How successful do you think you were in assisting the person? $(n=20)$

Very successful

Successful

Neither successful nor unsuccessful

Unsuccessful

Very unsuccessful

Q8. Would you like to comment on what happened? ${ }^{*}(n=20)$

Unaware of outcome because I didn't provide the first aid

The person received professional help

The person showed some signs of recovery

The person had made some changes, but am unsure how much recovery is progressing

Q9. Do you think the information in the 'Mental Health First Aid Training Course for Eating Disorders' contributed to the level of success you had in assisting the person? $(n=20)$

Very much

A little bit

Not sure

Not really 


\begin{tabular}{|c|c|c|}
\hline \multicolumn{3}{|c|}{$\begin{array}{l}\text { Q10. When assisting the person, did you do anything differently from what you would have done before attending the 'Mental Health First Aid Training } \\
\text { Course for Eating Disorders'? }(n=20)\end{array}$} \\
\hline Yes & 11 & 55.0 \\
\hline No & 4 & 20.0 \\
\hline Not sure & 5 & 25.0 \\
\hline \multicolumn{3}{|l|}{ Q11. If you answered 'yes' please provide a short description* $(n=11)$} \\
\hline Changed the way I approached the person & 7 & 63.6 \\
\hline Because I had more knowledge I noticed more symptoms & 4 & 36.4 \\
\hline Suggested professional help though wouldn't have before & 3 & 27.3 \\
\hline More understanding and supportive of the person & 2 & 18.2 \\
\hline \multicolumn{3}{|c|}{$\begin{array}{l}\text { Q12. Did you suggest to the person you were assisting that they should seek professional mental health care (e.g. from a GP, psychologist, psychiatrist) } \\
(n=20)\end{array}$} \\
\hline Yes & 10 & 50.0 \\
\hline No & 3 & 15.0 \\
\hline The person was already receiving mental health care & 3 & 15.0 \\
\hline Not sure & 4 & 20.0 \\
\hline \multicolumn{3}{|c|}{ Q13. As a result, did the person you were assisting seek mental health care from a professional? $(n=20)$} \\
\hline Not applicable & 6 & 30.0 \\
\hline Yes & 7 & 35.0 \\
\hline No & 0 & 0.0 \\
\hline Not sure & 7 & 35.0 \\
\hline
\end{tabular}

* Responses were open-ended and therefore participants may have mentioned multiple ideas/categories.

is perhaps not unexpected. While the treatment literature recognises the importance of friends and family in the help-seeking and recovery process, it is also apparent that the social network can have a negative influence on the development of mental illness and barriers to care $[72,73]$. It is therefore true that the effectiveness of individuals in facilitating help-seeking and recovery will depend on their level of knowledge, skill and empathy. As this concept was discussed as part of the training, it is perhaps not a surprise that 'helpful' ratings did not change across time. It is also important to acknowledge that this study is the first time the Knowledge of informal help-seeking scale had been implemented. Given its construction from just 4-items, further testing of its psychometric properties would further elucidate its utility in future evaluations of MHFA training. Furthermore, future evaluations may benefit from an examination of changes to inappropriate informal help-seeking, rather than a narrow focus on changes in the small number of appropriate strategies.

The FAKT showed that participant knowledge of first aid skills improved significantly after the training and, despite a drop-off in the follow-up period, this improvement was maintained at follow-up, indicating that the training was associated with a gain in knowledge that was sustained over time. As this is the first time the FAKT instrument has been implemented, the psychometric properties are not well known. It is therefore possible that increases from baseline to post-training were the result of re-test effects. However, given that there was a small drop in knowledge from post-training to follow-up, it appears that each re-testing event does not necessarily result in ongoing improvement over time.

Responses to the Mental Health First Aid item, which asked participants how they would help 'someone like Kelly', indicated that the training was associated with a significant increase in knowledge of the appropriate actions a person should take when providing a first aid intervention, as outlined by the MHFA action plan. However, this change was not sustained over time. There are two possible explanations for this result. One is that, given the open-ended response format for this item, participants provided less detailed responses at follow-up, due to their academic time constraints, and hence scored more poorly than at post-training. Another plausible explanation is that the training was insufficient in duration to produce a lasting effect. It is perhaps not unsurprising that participants could not remember these five specific actions, six months after receiving a 4-hour 
intervention. Furthermore, given that a previous evaluation of the full MHFA training program found an increase in knowledge of the action plan, which was maintained at six month follow-up [57], it is likely that had the current training involved more time to discuss and role-play the action plan, retention of information would have been maintained over time.

Overall, results for the items assessing knowledge showed that the training was associated with an immediate and lasting improvement in eating disorder problem recognition, knowledge of effective treatments, and consensus-based first aid strategies. Although results showed that there were increases in knowledge for informal help-seeking strategies and the MHFA action plan, these changes were not maintained over time, perhaps indicating that the intervention was too brief to produce lasting effects. These results do however provide preliminary support for the impact MHFA training can have on mental health literacy for eating disorders.

\section{Changes in attitudes}

Scores on the Social Distance Scale remained unchanged after the training and during the follow-up period, compared to baseline. Interestingly, in a review performed by Jorm and Oh [74], interventions aimed at reducing stigmatising attitudes of similar length to the current training, were found to have similar results whereby no significant changes in the total score were found over time. It therefore appears that the current intervention may have been too short and required more direct contact with people affected by eating disorders, to achieve the desired reduction in social distance.

The MHLQ-B item assessing participant ratings of how distressing they believed Kelly's problem would be, found that there were no significant differences associated with the training, despite some small fluctuations in ratings. Two plausible explanations for this result can been considered. First, it is possible that there was an insufficient 'dosing' effect, whereby the intervention was too short to provide lasting effects over time. If this were true, a longer intervention or booster session should produce the desired result. The second possibility is that participants were at ceiling when first measured at baseline. Given the high proportion of participants who rated Kelly's problem as either 'very' or 'extremely' distressing, it is possible that the intervention was unable to produce any further increase. As a point of comparison, a community-based survey of adolescent girls' mental health literacy for eating disorders found that most respondents believed that it would be 'very' $(40.0 \%)$ or 'extremely' distressing (45.0\%) to have a problem like Kelly's, indicating that there was little need for an intervention to educate participants about the distressing nature of the condition [75].
The desirability of bulimic symptoms was also assessed with a MHLQ-B item, which found that the majority of participants reported that they had 'never' or 'rarely' thought that 'it might not be too bad to be like Kelly given that she has been able to lose a lot of weight'. This finding is in contrast to previous evaluations of MHLQ$\mathrm{B}$, which have found much higher levels of desirability. The current finding may be an artefact of older adults and male participants being included in the sample, rather than a non-representative sample per se. That the desirability ratings remained stable over time and showed no significant change after the training, can be explained in two ways. First it is possible that the training had no effect on how desirable participants found bulimic symptoms. However, it is also possible that there was a ceiling effect. Given that it is expected the intervention would have the strongest effect among participants who considered bulimia desirable, though most did not indicate any desirability for bulimic symptoms at baseline, the beliefs of the current sample left little room for improvement.

Taken together, items assessing attitudes towards bulimia indicate that the sample at baseline were already empathic. It is therefore difficult to infer from these results whether the intervention was effective in changing attitudes about eating disorders. Although a sample with less empathic attitudes at baseline may have shown a statistically significant improvement after training, it remains a welcome finding that members of the community already express empathic attitudes towards individuals with eating disorders.

\section{Changes in behaviour}

The amount of contact participants had with individuals with eating disorders was measured using the Level of Contact Report and two Mental Health First Aid questions. Across all measures, there were no significant differences found between the amount of contact with individuals with eating disorders before the training and the amount of contact after the training. One possible explanation for this finding is that the environment in which the participants studied, worked and resided, was not amenable to producing a change in the amount of contact a participant may experience. For example, the large majority of students and staff undertake residence at a college for an academic year, beginning at the start of March and ending in late November. Between these months, there is very little change in the composition of staff or students in the residences. In the current study, the baseline measurement, training and follow-up period all fell within the 2010 academic year. Furthermore, because college residences are an environment where individuals live in very close contact with one another, and the welfare of students is closely monitored by pastoral 
care teams, it is possible that the majority of individuals with eating disorders, who were present within the residences, were already identified at baseline and this number could not be significantly improved upon after the training and during the follow-up period. Another possible explanation for the non-significant change in contact is that the training intervention had no effect on participant behaviour toward those with eating disorders. However, given that there was a significant increase in the ability to accurately recognise an eating disorder, that knowledge of effective first aid strategies significantly increased, and there was no increase in social distance, it appears unlikely that the intervention would not influence contact to some degree. A second and longer follow-up period, crossing over more than one academic year, may elucidate any effect of the college environment on the level of contact found among participants. However, it should be noted that some previous evaluations of MHFA training have also recorded no change in the level of contact with those with mental illness $[50,54]$.

The third Mental Health First Aid item was designed to measure change in the amount of help provided to those with eating disorders. No significant increase was found after the training. Some previous MHFA training evaluations have also failed to find an increase in amount of help provided. Of the four studies that have used the same method of evaluating help provided, two studies found no significant differences between baseline and follow-up [56,76].

The current study also found no change in the type of help provided by participants. Given the relatively small number of participants who reported providing first aid, it is possible that there was inadequate power to detect an effect. This postulate is supported by the finding that the majority of participants who provided first aid reported that they had done things differently to before they received the training, according to responses on the First Aid Experiences Questionnaire. Furthermore, the training was associated with a significant increase in participant confidence in providing first aid. In combination then, these results suggest that if a second and longer follow-up testing period was employed, which would allow participants more time to be in contact with and provide assistance to individuals with eating disorders, the existence of any significant changes in behaviour after the training, would be clarified.

Responses to the First Aid Experiences Questionnaire were largely positive, as many indicated that the training allowed them to feel more knowledgeable, confident and better prepared to recognise and provide assistance to someone developing or experiencing an eating disorder. Although the quantitative measures found no statistically significant increases in the amount of help provided, the open-ended information gathered by this instrument suggests that participants approached someone they were concerned about with more empathy and patience than before, and that this change was a result of the training. Furthermore, the majority of those who had not provided first aid indicated that the training had impacted on the way they viewed eating disorders as mental illnesses worthy of care, understanding and effective treatment. Interestingly, it appeared that the training generalised to assisting individuals with other mental health problems, as an equal proportion of participants reported providing first aid to individuals with mental illnesses other than eating disorders.

Participants who had provided first aid reported feeling reasonably successful in their intervention, however, many went on to explain that the unresolved nature of the person's illness contributed to their sense that their intervention was not a complete success. Given that this finding reiterates that of the earlier evaluation of guidelines being downloaded from the internet [58], future MHFA training would do well to include a discussion of what 'successful' first aid might look like and how participants should not expect immediate or necessarily complete recovery, as a result of providing assistance and facilitating appropriate treatment seeking. Interestingly, a much larger proportion of participants who reported assisting someone with another mental health problem reported feeling that their first aid intervention was successful. The ambivalence about success may therefore be particular to assisting in the case of an eating disorder.

Importantly, the First Aid Experiences Questionnaire provided no reports of adverse experiences associated with an attempted first aid intervention. Conversely, participants indicated that as a result of their suggestion and assistance, seven individuals had sought help for their suspected eating disorder, and an additional three were better supported whilst already receiving care. Furthermore, three participants mentioned assessing for suicide risk where they wouldn't have done so before the training. While statistical inferences from these data are not possible, it is encouraging that these responses indicate the training was associated with a higher level of effective assistance, and ultimately, more appropriate helpseeking.

In sum, the findings from instruments measuring behavior change suggest that there is some limited evidence for a change in first aid behaviours and an increase in appropriate help-seeking, albeit among a small number of participants. Many of the findings in the current research confer with those of previous MHFA evaluations employing a six month follow-up period, which suggests that a second and longer followup period, for example at 12 months after training, 
might allow for an increase in the size of the sample providing assistance, and thereby an increase in the power to detect any statistically significant effect of the training on behaviour change.

\section{Changes in mental health}

The EDE-Q and K10 were implemented to assess any changes in the mental health of participants. Given previous research evaluating preventive interventions for eating disorders has found that providing information about eating disorder symptoms can lead to an increase in eating pathology, the EDE-Q was used in the current study to assess for any negative impact on participants. Despite being normative at baseline, the sample's average global EDE-Q score was found to be significantly lower at follow-up. There are two possible explanations for this outcome. The first is that the intervention had a positive effect on eating pathology. The second is that the result is due to a re-test effect, whereby scores improved (decreased) with each testing occasion, as has been shown to be possible with psychiatric instruments designed to assess negative selfcharacteristics [77]. Without the presence of a control group to assess whether there is an inherent decrease in scores on the EDE-Q across time, it is not possible to conclude which of the two explanations is the more plausible. In any case, the current findings suggest no evidence that the training had a negative impact on the eating pathology of participants.

Although there was a slight decrease in K10 total scores from baseline to follow-up, this was not statistically significant. This finding is in accordance with previous evaluations of MHFA training and other mental health literacy interventions, and suggests that the training does not have a negative impact on the psychological distress of participants.

\section{Limitations}

The absence of a control group is the primary limitation of this research. Without being able to control for extraneous variability in scores over time, concrete conclusions about the role of the training in causing improvements on a number of measures, such as the FAKT and EDE-Q, cannot be reached. However, given that the current research was designed to be a preliminary exploration of how the concept of mental health first aid might be applied to eating disorders, this study has produced some initial evidence to suggest that providing a training intervention to community members increases knowledge and confidence in providing first aid, as well as important data about how future evaluations could be best implemented.

A second limitation of this research is the composition of the sample at baseline. Prior to training, the majority of participants upheld empathic attitudes towards people with bulimia, had relatively good mental health literacy, a large proportion were already in contact with an individual with an eating disorder and had provided some level of assistance. In contrast to the community studies completed by Mond and colleagues, it appears as though the current sample were already functioning above average on a number of variables [e.g. [46,49,75,78]. It was perhaps the nature of the residential college environment, where students live in close contact with one another, members of staff are highly trained in providing pastoral care, and all are well educated, which resulted in participants scoring relatively highly on most measures at baseline. It is also possible that because recruitment materials contained information about both eating disorders and mental health first aid, participants with favourable baseline scores enroled in this study. Research that had a much longer time frame for recruiting participants and could engage interested parties in more subtle ways, may have resulted in a different sample composition.

A third limitation of this research is the size of the sample who reported providing a first aid intervention. Although the proportion of participants who reported providing some form of help $(n=31,42 \%)$ was similar to previous evaluations of MHFA training [e.g. [56], the power to uncover a statistically significant effect is limited by such small numbers. Importantly, the only investigation to examine first aid experiences in a follow-up period longer than six months, found that $78 \%$ of respondents had experienced a situation in which they had provided some help, 19 to 21 months after receiving the training [55]. To ensure sufficient statistical power in future research evaluating MHFA training, a combination of a larger number of trained participants and a longer follow-up period should be employed.

\section{Implications of this research}

Across most measures of knowledge, significant improvements were found from baseline to post-training. However, these changes were often not maintained at follow-up, as sharp declines occurred in the follow-up period. That the current research was not able to find sustained effects for a number of instruments suggests that the duration or 'dosing' effect of the training was inadequate. Given that evaluations of the full MHFA training program, which is presented across four sessions and totals 12 hours, has found much stronger effects at six month follow-up, it would be beneficial for the field of eating disorders for future research to investigate the effect of providing the current training within the full MHFA syllabus. It is also possible that presenting the current training over two or three sessions, with the inclusion of more material focused on the reduction of stigmatising attitudes and modeling of first aid behaviours, would produce lasting significant 
changes to knowledge, attitudes and behaviours. Such change would no doubt be important in encouraging those with eating disorders to seek appropriate help early, and thereby reduce the current heavy burden associated with these illnesses.

\section{Conclusions}

Despite the short duration of the training's impact, this research has provided preliminary evidence that mental health first aid training for eating disorders is associated with an increase in accurate recognition of eating disorders, knowledge of effective treatments and consensusbased first aid strategies, and confidence in providing help. The training was also associated with appropriate treatment seeking and appropriate first aid strategies, in a number of first aid interventions provided by participants to individuals with suspected eating disorders. Furthermore, there was no evidence that the training had a negative impact on the mental health of participants or the first aid they provided to others. Future research is needed to elucidate the optimal duration of the training program to achieve sustained increases in knowledge and attitudes, and to assess whether significant changes in first aid behaviour emerge over time. The current investigation, however, can confirm that the concept of mental health first aid can be usefully applied to improve mental health literacy and help-seeking behaviours for the eating disorders.

\section{Additional file}

Additional file 1: Document 1. Results from the First Aid Experiences Questionnaire. This file contains a description of the qualitative data collected using the First Aid Experiences Questionnaire, which assessed the nature of the first aid interventions provided by participants who attended the mental health first aid training for eating disorders program.

\section{Competing interests}

AFJ is the scientific director of of Mental Health First Aid International.

\section{Authors' contributions}

This research was completed towards the fulfillment of the degree of doctor of philosophy for LMH. AFJ was the primary, and SJP was the secondary, academic supervisor. All authors made substantial contributions to the conception and design of the research, and to the analysis and interpretation of data. All authors were involved in drafting and revising this manuscript and have given this version final approval to be published.

\section{Acknowledgements}

Funding for this research was provided via an lan Scott PhD Scholarship from Australian Rotary Health awarded to LMH and a PhD top-up scholarship from the Butterfly Foundation awarded to LMH.

\section{Author details}

${ }^{1}$ Melbourne School of Population Health, University of Melbourne, Parkville VIC Australia. ${ }^{2}$ School of Psychological Science, La Trobe University, Bundoora VIC Australia.

Received: 28 October 2011 Accepted: 14 May 2012

Published: 2 August 2012

\section{References}

1. Bacaltchuk J, Hay PJ, Trefiglio R: Antidepressants versus psychological treatments and their combination for bulimia nervosa. Cochrane Database Syst Rev 2001, (4):1-27. DOI: 10.1002/14651858.CD003385. Art. No.: CD003385.

2. Hay PJ, Bacaltchuk J, Stefano S: Psychotherapy for bulimia nervosa and binging. Cochrane Database Syst Rev 2004, 2(3):1-127. DOI: 10.1002/ 14651858.CD000562.pub2. Art. No.: CD000562.

3. Fairburn CG, Norman PA, Welch SL, Oconnor ME, Doll HA, Peveler RC: A prospective study of outcome in bulimia nervosa and the long-term effects of three psychological treatments. Arch Gen Psychiatry 1995, 52:304-312.

4. Claudino AM, Lima MS, Hay PJ, Bacaltchuk J, Schmidt UU, Treasure JL: Antidepressants for anorexia nervosa. Cochrane Database Syst Rev 2006, (1):1-50. DOI: 10.1002/14651858.CD004365.pub2. Art. No.: CD004365.

5. Fisher CA, Hetrick SE, Rushford N: Family therapy for anorexia nervosa. Cochrane Database Syst Rev 2010, pub2(4):1-110. DOI: 10.1002/14651858. CD004780.

6. Vanderycken $\mathrm{W}$ : The place of inpatient care in the treatment of anorexia nervosa: questions to be answered. Int J Eat Disord 2003, 34:409-422.

7. Jenkins PE, Hoste RR, Meyer C, Blissett JM: Eating disorders and quality of life: a review of the literature. Clin Psychol Rev 2011, 31:113-121.

8. Berkman ND, Lohr KN, Bulik CM: Outcomes of eating disorders: a systematic review of the literature. Int J Eat Disord 2007, 40:293-309.

9. Hart LM, Granillo MT, Jorm AF, Paxton SJ: Unmet need for treatment in the eating disorders: a systematic review of eating disorder specific treatment seeking among community cases. Clin Psychol Rev 2011, 31:727-735.

10. Hay PJ, Marley J, Lemar S: Covert eating disorders: the prevalence, characteristics and help-seeking of those with bulimic eating disorders in general practice. Primary Care Psychiatry 1998, 4:95-99.

11. Hay PJ, Loukas A, Philpott H: Prevalence and characteristics of men with eating disorders in primary care: How do they compare to women and what features may aid in identification? Primary Care and Community Psychiatry 2005, 10:1-6.

12. Mond JM, Hay PJ, Darby A, Paxton SJ, Quirk F, Buttner P, Owen C, Rodgers $B$ : Women with bulimic eating disorders: when do they receive treatment for an eating problem? J Consult Clin Psychol 2009, 77:835-844.

13. Evans EJ, Hay PJ, Mond JM, Paxton SJ, Quirk F, Rodgers B, Jhajj AK, Sawoniewska MA: Barriers to help-seeking in young women with eating disorders: a qualitative exploration in a longitudinal community survey. Eat Disord 2011, 19:270-285.

14. Mond JM, Hay PJ, Rodgers B, Owen C, Mitchell JE: Correlates of the use of purging and non-purging methods of weight control in a community sample of women. Aust N Z J Psychiatry 2006, 40:136-142.

15. Mond JM, Hay PJ, Rodgers B, Owen C: Health service utilization for eating disorders: findings from a community-based study. Int J Eat Disord 2007, 40:399-408.

16. Hepworth NS, Paxton SJ, Williams B: Predictors of attitudes towards treatments for bulimia nervosa. Aust N Z J Psychiatry 2007, 41:247-256.

17. Perkins SJ, Murphy R, Schmidt U, Williams C: Self-help and guided self-help for eating disorders. Cochrane Database of Systematic Reviews 2006, (3):186. DOl: 10.1002/14651858.CD004191.pub2. Art. No.: CD004191.

18. Agras WS: The consequences and costs of the eating disorders. Psychiatr Clin North Am 2001, 24:371-379.

19. Begg S, Vos T, Barker B, Stevenson C, Stanley L: Lopez AD: The Burden of Disease and Injury in Australia 2003. Canberra: Australian Institute of Health and Welfare; 2007.

20. Hay PJ, Mond JM: How to 'count the cost' and measure burden? A review of health-related quality of life in people with eating disorders. J Ment Health 2005, 14:539-552.

21. Hepworth NS, Paxton SJ: Pathways to help-seeking in bulimia nervosa and binge eating problems: a concept mapping approach. Int J Eat Disord 2007, 40:493-504.

22. Jorm AF, Korten AE, Jacomb PA, Christensen H, Rodgers B, Pollitt P: "Mental health literacy": a survey of the public's ability to recognise mental disorders and their beliefs about the effectiveness of treatment. Medical Journal of Australia 1997, 166:182-186.

23. Jorm AF, Wright A, Morgan AJ: Where to seek help for a mental disorder? National survey of the beliefs of Australian youth and their parents. Medical Journal of Australia 2007, 187:556-560. 
24. Vogel DL, Wade NG, Wester SR, Larson L, Hackler AH: Seeking help from a mental health professional: the influence of one's social network. J Clin Psychol 2007, 63:233-245.

25. Treasure $\mathrm{L}$, Sepulveda AR, Whitaker W, Todd G, Lopez C, Whitney J: Collaborative care between professionals and non-professionals in the management of eating disorders: a description of workshops focussed on interpersonal maintaining factors. European Eating Disorder Review 2007, 15:24-34.

26. Treasure JL, Sepulveda AR, McDonald P, Whitaker W, Lopez C, Zabala MJ, Kyriacou M, Todd G: Interpersonal maintaining factors in eating disorder: skill sharing interventions for carers. International Journal of Child and Adolescent Health 2008, 1:331-338.

27. Kitchener BA, Jorm AF, Kelly CM: Mental Health First Aid Manual. 2nd edition. Melbourne: Orygen Youth Health Research Centre; 2010.

28. Jorm AF, Korten AE, Jacomb PA, Christensen H, Rodgers B, Pollitt P: Public beliefs about causes and risk factors for depression and schizophrenia. Soc Psychiatry Psychiatr Epidemiol 1997, 32:143-148.

29. Kitchener BA, Jorm AF: Mental Health First Aid: an international programme for early intervention. Early Interv Psychiatry 2008, 2:55-61.

30. Kelly CM, Jorm AF, Kitchener BA, Langlands RL: Development of mental health first aid guidelines for deliberate non-suicidal self-injury: a delphi study. BMC Psychiatry 2008, 8:62.

31. Kelly CM, Jorm AF, Kitchener BA, Langlands RL: Development of mental health first aid guidelines for suicidal ideation and behaviour: A delphi study. BMC Psychiatry 2008, 8:17.

32. Kelly CM, Jorm AF, Kitchener BA: Development of mental health first aid guidelines for panic attacks: a delphi study. BMC Psychiatry 2009, 9:49.

33. Kelly CM, Jorm AF, Kitchener BA: Development of mental health first aid guidelines on how a member of the public can support a person affected by a traumatic event: a delphi study. BMC Psychiatry 2010, 10:49.

34. Kingston AH, Jorm AF, Kitchener BA, Hides L, Kelly CM, Morgan AJ, Hart LM, Lubman DI: Helping someone with problem drinking: mental health first aid guidelines - a Delphi expert consensus study. BMC Psychiatry 2009, 9:79.

35. Kingston AH, Morgan AJ, Jorm AF, Hall K, Hart LM, Kelly CM, Lubman DI: Helping someone with problem drug use: a delphi consensus study of consumers, carers, and clinicians. BMC Psychiatry 2011, 11:3.

36. Langlands RL, Jorm AF, Kelly CM, Kitchener BA: First aid for depression: a delphi consensus study with consumers, carers and clinicians. J Affect Disord 2008, 105:157-165.

37. Langlands RL, Jorm AF, Kelly CM, Kitchener BA: First aid recommendations for psychosis: using the delphi method to gain consensus between mental health consumers, carers, and clinicians. Schizophr Bull 2008, 34:435-443.

38. Jorm AF, Kitchener BA: Noting a landmark achievement: mental health first aid training reaches $1 \%$ of Australian adults. Aust N Z J Psychiatry 2011, 45:808-813.

39. Kitchener BA, Jorm AF: Mental health first aid training: review of evaluation studies. Aust N Z J Psychiatry 2006, 40:6-8.

40. Minas $H$, Colucci $E$, Jorm AF: Evaluation of mental health first aid training with members of the Vietnamese community in Melbourne. Australia. International Journal of Mental Health Systems 2009, 3:19.

41. Jorm AF: Public knowledge and awareness about mental illnesses. In Oxford Textbook of Community Mental Health. Edited by Thornicroft G, Szmukler G, Mueser K, Drake R. Oxford: Oxford University Press; 2011.

42. Hart LM, Jorm AF, Paxton SJ, Kelly CM, Kitchener BA: First aid for eating disorders. Eating Disorders: The Journal of Treatment and Prevention 2009, 17:357-384

43. The University of Melbourne: Facts and figures about the University. http://www. fpg.unimelb.edu.au/ipeq/facts-figures.html. Accessed 11 November 2010.

44. Schwitzer AM, Bergholz K, Dore T, Salimi L: Eating disorders among college women: prevention, education, and treatment responses. J Am Coll Health 1998, 46:199-207.

45. Striegel-Moore RH, Bulik CM: Risk factors for eating disorders. Am Psychol 2007, 62:181-198.

46. Mond JM, Marks P, Hay PJ, Rodgers B, Kelly CM, Owen C, Paxton SJ: Mental health literacy and eating-disordered behavior: beliefs of adolescent girls concerning the treatment of and treatment-seeking for bulimia nervosa. J Youth Adolesc 2007, 36:753-762.

47. Prouty AM, Protinsky HO, Canady D: College women: eating behaviors and help-seeking preferences. Adolescence 2002, 37:353-363.
48. Mental Health First Aid Training and Research Program: Eating Disorders: First aid guidelines. Melbourne: Orygen Youth Health Research Centre; 2008

49. Mond JM, Hay PJ, Rodgers B, Owen C, Beumont PJV: Beliefs of women concerning the severity and prevalence of bulimia nervosa. Soc Psychiatry Psychiatr Epidemiol 2004, 39:299-304.

50. Kitchener BA, Jorm AF: Mental health first aid training for the public: evaluation of effects on knowledge, attitudes and helping behavior. BMC Psychiatry 2002, 2:10

51. Link BG, Cullen FT, Frank J, Wozniak JF: The social rejection of former mental patients: understanding why labels matter. Am J Sociol 1987, 92:1461-1500

52. Link BG, Phelan JC, Bresnahan M, Stueve A, Pescosolido BA: Public conceptions of mental illness: labels, causes, dangerousness, and social distance. Am J Public Health 1999, 89:1328-1333.

53. Holmes EP, Corrigan PW, Williams P, Canar J, Kubiak MA: Changing attitudes about schizophrenia. Schizophr Bull 1999, 25:447-456.

54. Jorm AF, Kitchener BA, O'Kearney R, Dear K: Mental health first aid training of the public in a rural area: a cluster randomized trial. BMC Psychiatry 2004, 4:33.

55. Jorm AF, Kitchener BA, Mugford SK: Experiences in applying skills learned in a mental health first aid training course: a qualitative study of participants' stories. BMC Psychiatry 2005, 5:43.

56. Kitchener BA, Jorm AF: Mental health first aid training in a workplace setting: a randomized controlled trial. BMC Psychiatry 2004, 4:23.

57. Kelly CM, Mithen JM, Fischer J, Kitchener BA, Jorm AF, Lowe AJ, Scanlan C: Youth Mental Health First Aid: a description of the program and an initial evaluation. International Journal of Mental Health Systems 2011, 5:4.

58. Hart LM, Jorm AF, Paxton SJ, Cvetkovski S: Mental health first aid guidelines: An evaluation of impact following download from the world wide web. Early Interv Psychiatry. In press.

59. Carter JC, Stewart DA, Dunn VJ, Fairburn CG: Primary prevention of eating disorders: might it do more harm than good? Int J Eat Disord 1997, 22:167-172.

60. Mann T, Nolen-Hoeksema S, Huang K, Burgard D, Wright A, Hanson K: Are two interventions worse than none? Joint primary and secondary prevention of eating disorders in college females. Health Psychol 1997 16:10

61. Fairburn CG, Beglin SJ: Assessment of eating disorders: interview or self-report questionnaire. Int J Eat Disord 1994, 16:363-370.

62. Peterson CB, Mitchell JE: Self-report measures. In Assessment of Eating Disorders. Edited by Mitchell JE, Peterson CB. New York: Guilford Press; 2005:98-119.

63. Mond JM, Hay PJ, Rodgers B, Owen C, Beumont PJV: Validity of the Eating Disorder Examination Questionnaire (EDE-Q) in screening for eating disorders in community samples. Behav Res Ther 2004, 42:551-567.

64. Peterson CB, Crosby RD, Wonderlich SA, Joiner T, Crow SJ, Mitchell JE, Bardone-Cone AM, Klein M, le Grange D: Psychometric properties of the Eating Disorder Examination-Questionnaire: factor structure and internal consistency. Int J Eat Disord 2007, 40:386-389.

65. Mond JM, Myers TC, Crosby RD, Hay PJ, Rodgers B, Morgan JF, Hubert Lacey J, Mitchell JE: Screening for eating disorders in primary care: EDE-Q versus SCOFF. Behav Res Ther 2008, 46:612-622.

66. Mond JM, Hay PJ, Rodgers B, Owen C, Beumont PJV: Temporal stability of the eating disorder examination questionnaire. Int J Eat Disord 2004, 36:195-203.

67. Andrews G, Slade T: Interpreting scores on the Kessler Psychological Distress Scale (K10). Aust N Z J Public Health 2001, 26:494-498.

68. Field AP: Discovering Statistics Using SPSS. 3rd edition. London: Sage; 2009.

69. Siegel S: Nonparametric Statistics for the Behavioral Sciences. New York, NY: McGraw Hill; 1956.

70. Mond JM, Hay PJ, Rodgers B, Owen C: Eating Disorder Examination Questionnaire (EDE-Q): Norms for young adult women. Behav Res Ther 2006, 44:53-62.

71. Lavender JM, De Young KP, Anderson DA: Eating Disorder Examination Questionnaire (EDE-Q): norms for undergraduate men. Eat Behav 2010, 11:119-121.

72. Taylor CB, Bryson S, Celio Doyle AA, Luce KH, Cunning D, Abascal LB, Rockwell R, Field AE, Striegel-Moore RH, Winzelberg AJ, Wilfley DE: The adverse effect of negative comments about weight and shape from family and siblings on women at high risk for eating disorders. Pediatrics 2006, 118:731-738. 
73. Roberts SJ: Social support and help-seeking: review of the literature. Advances in Nursing Science 1988, 10:1-11.

74. Jorm AF, Oh E: Desire for social distance from people with mental disorders. Aust N Z J Psychiatry 2009, 43:183-200.

75. Mond JM, Marks P: Beliefs of adolescent girls concerning the severity and prevalence of bulimia nervosa. Australian Journal of Psychology 2007, 59:87-93.

76. Jorm AF, Kitchener BA, Sawyer M, Scales H, Cvetkovski S: Mental health first aid training for high school teachers: a cluster randomized trial. $B M C$ Psychiatry 2010, 10:51.

77. Jorm AF, Duncan-Jones P, Scott R: An analysis of the re-test artefact in longitudinal studies of psychiatric symptoms and personality. Psychol Med 1989, 19:487-493.

78. Mond JM, Hay PJ, Rodgers B, Owen C, Beumont PJV: Beliefs of women concerning causes and risk factors for bulimia nervosa. Aust N Z J Psychiatry 2004, 38:463-469.

doi:10.1186/1471-244X-12-98

Cite this article as: Hart et al.: Mental health first aid for eating

disorders: pilot evaluation of a training program for the public. BMC

Psychiatry 2012 12:98.

\section{Submit your next manuscript to BioMed Central and take full advantage of:}

- Convenient online submission

- Thorough peer review

- No space constraints or color figure charges

- Immediate publication on acceptance

- Inclusion in PubMed, CAS, Scopus and Google Scholar

- Research which is freely available for redistribution 